\title{
Perspective: Point/Counterpoint Atypical Depression: Useful Concept, but it's Time to Revise the DSM-IV Criteria
}

\author{
Michael E Thase*, I \\ 'Department of Psychiatry, University of Pennsylvania School of Medicine and Philadelphia Veterans Affairs Medical Center, Philadelphia, \\ PA, USA
}

\begin{abstract}
Stewart et al (2009) have outlined the evidence in support of the validity of the DSM-IV definition of the 'With Atypical Features' episode specifier. Although recognizing the historical significance and clinical utility of the concept of atypical depression, this article takes issue with the DSM-IV criteria. It is concluded that mood reactivity, the A or obligative criterion, is neither significantly associated with the other symptomatic criteria nor useful to diagnose atypical depression, and thus should be eliminated. Problems with operationalization, specification, and reliability of ratings of the diagnostic criteria further limit validity. Despite these limitations in classification, many of the features associated with atypical depression are linked to an early onset of affective illness, including trait-like interpersonal sensitivity, comorbid social anxiety and agoraphobia, a history of childhood physical or sexual trauma, and indicators of the 'soft' side of the bipolar spectrum. Neurophysiologic studies also suggest that chronic, early-onset atypical depressions differ from both melancholia and normality. Re-analyses of the Columbia group's seminal studies suggest that preferential response to phenelzine vs imipramine-arguably the strongest validator of atypical depression - similarly appears to be limited to patients with chronic, early-onset syndromes. The criteria for atypical depression need to be revised in DSM-V, including sharpening the operational definitions for the specific symptoms. The importance of age of onset and comorbid anxiety warrant further study. Research examining the validity of a subform of atypical depression characterized by trait-like interpersonal sensitivity and a chronic, early-onset course may further enhance the clinical utility of the DSM-V classification.
\end{abstract}

Neuropsychopharmacology (2009) 34, 2633-264I; doi:I0.1038/npp.2009. 100; published online 9 September 2009

Keywords: DSM-IV; atypical depression; MAOls; mood reactivity; reverse neurovegetative features

\section{INTRODUCTION}

The construct of atypical depression is nearly as old as psychopharmacology itself, dating to within a few years of the introduction of the first antidepressant medications, imipramine - a tricyclic antidepressant (TCA) - and iproniazid - a monoamine oxidase inhibitor (MAOI) (Sargant, 1960; West and Dally, 1959). Despite its considerable historical importance in the psychiatric literature, particularly with respect to the differential therapeutics of depressive disorders, atypical depression was not included in the official nomenclature of the American Psychiatric Association until DSM-IV (American Psychiatric Association, 1994). At that time, the term 'With Atypical Features' was added as a specifier for major depressive episodes (for both bipolar and nonbipolar disorders) and dysthymia. More than a decade later, however, controversy persists

*Correspondence: Dr ME Thase, Department of Psychiatry, University of Pennsylvania School of Medicine and Philadelphia Veterans Affairs Medical Center, 3535 Market Street, Suite 670, Philadelphia, PA |5213-2593, USA, Tel: + | 215746 6680, Fax: + 12155730759 , E-mail: thase@mail.med.upenn.edu

Received 7 August 2006; revised 2 November 2006; accepted 10 November 2006 about the validity of both the construct and the DSM-IV criteria (see, eg, Parker et al, 2002, 2005). In anticipation of deliberations that will lead to DSM-V, it is timely to review the evidence for - and against - the current definition of atypical depression. In an accompanying article in this issue of Neuropsychopharmacology, Stewart et al (2009) review the evidence in support of the validity of the DSM-IV criteria for atypical depression. This is most fitting because the work of Klein, Quitkin, Stewart, and their colleagues at the New York State Psychiatric Institute and Columbia University College of Physicians and Surgeons was unarguably the most influential in shaping the DSM-IV criteria (Quitkin et al, 1993; Rabkin et al, 1996; Stewart et al, 1993). Despite the historical and heuristic value of the concept of atypical depression, I will take the negative side of the point-counterpoint exchange in this article, arguing that the weight of the evidence indicates that the criteria for atypical depression will need to be revised in DSM-V.

\section{Dichotomous Classifications of Mood Disorders}

The DSM-IV criteria used to define 'With Atypical Features' as a specifier for episodes of major depression and 
Table I Summary of DSM-IV Criteria for with Atypical Features Episode Specifier

May be used to characterize MDEs (bipolar and MDD) and dysthymia

Predominant clinical state over past 2 weeks (MDE) or 2 years (dysthymia)

Requires $\mathrm{A}+$ at least two from $\mathrm{B}$

$A$ : Mood must be reactive to actual or anticipated positive events

B: (Associated features)

I. Significant weight gain or increased appetite

2. Hypersomnia

3. Leaden paralysis

4. Interpersonal rejection sensitivity

Source: American Psychiatric Association (1994).

dysthymia are summarized in Table 1 . The DSM-IV makes a distinction between a formal subtype of a disorder and an episode specifier and atypical depression-like melancholia-was judged to fall in the latter category. Without challenging the wisdom of this decision, I will use the less cumbersome term 'atypical depression' in this paper interchangeably with the episode specifier 'With Atypical Features' unless otherwise noted.

Whether or not one accepts the DSM-IV position on subtypes $v s$ episode specifiers, the very term atypical implicitly imposes a binary structure to classification and presumes that another, larger group of patients will manifest the other, more typical presentation. As dichotomous models of classification have dominated the taxonomy of mood disorders for the past 50 years, this approach has a strong historical legacy.

Dating at least to the seminal study of Gillespie (1929), a dominant view among hospital-based psychiatrists was that depressions could be divided into endogenous (ie, an autonomous, more severe, and biologically mediated illness) and nonendogenous (ie, a less severe, more mood reactive, and neurotic environmentally mediated illness) subtypes. Endogenous depression lives on in the DSM-IV episode specifier 'With Melancholic Features.' From a historical vantage point, it is easy to understand how West and Dally (1959) came to view the depressions that responded to the MAOI iproniazid as both atypical and a unique subform of nonendogenous depression. On the one hand, their patients did not manifest the classical features of endogenous depression and they were not particularly responsive to the treatments that were known to be reliably effective for severe depressions (ie, imipramine and electroconvulsive therapy). On the other hand, in marked contrast to the prevailing view that neurotic disorders were not responsive to somatic therapies (and, by implication, better treated with psychotherapy), their patients were quite responsive to the MAOI. The wonderful simplicity of the resulting interaction between depressive subtype and specific type of antidepressant was no doubt compelling in those heady early days of biological psychiatry. As discussed subsequently, the therapeutic landscape in 2009 is considerably more complex and such a parsimonious formulation (ie, two syndromes, two treatments of choice) is no longer operative.

\section{Anxiety or Reverse Vegetative Symptoms? Historical Perspectives}

The historical continuity of the concept of atypical depression across 60 years conceals the fact that the original descriptions by West and Dally (1959) and Sargant (1960) only partly overlap with the DSM-IV criteria. The early observations and the DSM-IV criteria do agree that patients with atypical depression do not have endogenous depression/melancholia. There is also agreement that patients with atypical depression complain of extreme fatigue and exhibit some form of emotional over-reactivity. However, one important difference between the older and newer perspectives is that, although the patients described by West and Dally (1959) and Sargant (1960) were said to have good premorbid adjustment (ie, their patients' emotional overreactivity was viewed as state-dependent), the DSM-IV criteria state that the pattern of interpersonal rejection sensitivity' is both long-standing and is not limited to episodes of mood disturbance (American Psychiatric Association, 1994). Perhaps more remarkably, the reverse neurovegetative symptoms such as overeating/weight gain and hypersomnia that figure so prominently in the DSM-IV criteria, accounting for two of four of the associated ' $\mathrm{B}$ ' symptoms (American Psychiatric Association, 1994), were not even noted by West and Dally (1959) and mentioned only in passing by Sargant (1960). Instead, the early descriptions emphasized significant state-dependent anxiety, particularly multiple phobias (Sargant, 1960; West and Dally, 1959), which are not included in the DSM-IV criteria.

Greater emphasis on the relevance of reverse neurovegetative features to MAOI response began with a paper by Pollitt (1965) and subsequently linked to emotional overreactivity through the concept of hysteroid dysphoria (Klein and Davis, 1969; Klein and Liebowitz, 1982; Liebowitz and Klein, 1979; Quitkin et al, 1979). By the time that Klein's research group began a series of trials contrasting the MAOI phenelzine with imipramine, overeating/weight gain and hypersomnia figured prominently in the research diagnostic criteria for atypical depression (Liebowitz et al, 1988; McGrath et al, 1993; Quitkin et al, 1988, 1991). As these studies unequivocally established the superiority of phenelzine over imipramine, the so-called Columbia criteria for atypical depression were adopted with slight modification for DSM-IV. Despite the historical and conceptual significance of anxiety to the construct of atypical depression (ie Davidson et al, 1982), there are no pertinent criteria included in the DSM-IV definition.

\section{Validity of DSM-IV Atypical Depression}

The research that led to inclusion of atypical depression in DSM-IV has been nicely summarized by the Columbia group (Quitkin et al, 1993; Rabkin et al, 1996; Stewart et al, 1993). The accompanying review by Stewart et al (2009), which applies the Washington University approach to validating diagnoses, summarizes much of the relevant research conducted since the publication of DSM-IV. They review research using five external validators: syndromal features, course of illness, biologic correlates, family history, and treatment response. We can agree that DSM-IV atypical 
depression differs significantly from melancholia and that this distinction is valid. We do not agree, however, that the DSM-IV criteria optimally and meaningfully distinguish atypical depression from other nonmelancholic depressive states, whether classified as nonbipolar, dysthymic, or bipolar subtypes of mood disorder. What follows is an alternative appraisal of the relevant studies, aimed at pointing to necessary revisions in the DSM-IV and highlighting directions for further research.

Syndromal characteristics. According to DSM-IV, mood reactivity is the only ' $\mathrm{A}$ ' or obligative characteristic of all atypical depressions. Parker et al (2002) questioned the usefulness of this choice, noting that it is the loss of mood reactivity that is pathologic and that it is problematic to define a condition with a nonpathologic (ie, normal) characteristic. As melancholia is an exclusion criterion for atypical depression in DSM-IV and loss of mood reactivity is one of the ' $\mathrm{A}$ ' criteria for melancholia, it would appear that the requirement of preserved mood reactivity in atypical depression is largely redundant. In any case, relatively few nonmelancholic depressed outpatients have a truly autonomous mood disturbance (Posternak and Zimmerman, 2002); hence, a broad definition of mood reactivity excludes only a small number of patients who might otherwise meet criteria of atypical depression.

The findings of four studies suggest that mood reactivity is not only a redundant criterion but it also has questionable validity as one of the criteria of atypical depression (Henkel et al, 2004; Parker et al, 2002; Posternak and Zimmerman, 2002). For example, in the psychiatric outpatients studied by Posternak and Zimmerman (2002), mood reactivity was not associated with an increased incidence of any of the associated features of DSM-IV atypical depression. After stratifying their study group with respect to mood reactivity, they found that the almost identical proportions of patients reported at least two of the associated symptoms of atypical depression (mood reactivity present: $31 \%$; mood not reactive: $32 \%)$.

Parker et al $(2002,2005)$ reached a similar conclusion in the second study, despite using a much narrower definition of mood reactivity. (ie, only 69 of $150(46 \%)$ of their patients were rated as having a reactive mood). In their data set, in which only $46 \%$ of patients were rated as having a reactive mood, those who met the A criterion again had no greater incidence of hypersomnia, hyperphagia, and rejection sensitivity than patients with nonreactive moods. Mood reactivity was, in fact, associated with a decreased incidence of extreme fatigue/leaden paralysis. Patients were almost equally likely to report two or more of the associated symptomatic features of atypical depression, with rates of $38 \%$ (mood reactive) and 39\% (mood nonreactive), respectively.

In the third study, which included 403 depressed patients treated in 20 primary care practices in Germany, Henkel et al (2004) used a statistical technique known as configurational frequency analysis to study patterns of association among the DSM-IV criteria for atypical depression. They found mood reactivity was associated with only one significant syndromal configuration: the absence of the any of the four associated symptoms of atypical depression.
Most recently, Novick et al (2005) examined the symptoms and correlates of atypical depression in 1455 participants of the Sequenced Treatment Alternatives to Relieve Depression $\left(\mathrm{STAR}^{\star} \mathrm{D}\right)$ study. Beyond the size of the sample, a unique feature of the STAR*D project is that patients were drawn from 41 geographically and ethnically diverse primary care and nonresearch psychiatric outpatient clinics across the United States. Thus, although this is a clinical sample of individuals seeking treatment for major depressive disorder, it is nearly as representative as one selected for an epidemiologic study. In this analysis, atypical depression was operationally defined on the basis of the relevant items of the Inventory of Depressive Symptoms (30 item, clinician-administered version) (Rush et al, 1996). About one-fifth of the sample (264 of 1455) met the DSM-IV criterion for 'with atypical features': this subgroup was more likely to be female, have an earlier age of onset, and manifest higher levels of comorbidity and greater symptom severity. Despite the requirement that patients must score $<2$ on the mood reactivity question in order to be classified as 'with atypical features', scores on this item-unlike those for all of the remaining criteria-did not differentiate between the groups.

It is also noteworthy that the atypical depression construct has been validated in a number of large psychometric studies that did not even assess mood reactivity (Horwath et al, 1992; Kendler et al, 1996; Korszun et al, 2004; Levitan et al, 1997; Matza et al, 2003; Sullivan et al, 2002). Despite differences in statistical methods and populations, in each case the presence of reverse vegetative symptoms identified a distinct subgroup of depressed individuals, without consideration of preservation or loss of mood reactivity.

In a prospective study of a Swiss community sample, Angst et al (2002) rated mood reactivity, but chose not to use it as a hierarchical criterion (ie, it was no more or less important than the other four criteria). Among the subset of patients classified as having atypical depression on the basis of any three of the criteria, mood reactivity was the most common symptom, present in $89 \%$ of men and $90 \%$ of women. However, rejection sensitivity, leaden paralysis, and oversleeping were nearly as common (ranging from 78 to $84 \%)$. They concluded that their findings did not support the use of a hierarchical ranking of mood reactivity to diagnose atypical depression. They expanded upon this impression in a more recent analysis (Angst $e t$ al, 2006) and concluded that the diagnosis of atypical depression could be made with equal utility if either three of five criteria (including mood reactivity) or two of four criteria (excluding mood reactivity) were used.

Finally, although studies of pharmacological response in atypical depression will largely be addressed in a subsequent section, reactive mood appears to be unrelated to differential response to TCAs and MAOIs. For example, in one study by the Columbia group, patients with reactive mood-but none of the remaining criteria for atypical depression - were as likely to respond to imipramine as they were to phenelzine (Quitkin et al, 1989). Case series by the Columbia group also illustrate the converse, ie, that response to MAOIs is not delimited to patients with reactive moods (McGrath et al, 1984, 1986; Quitkin et al, 1981). The Pittsburgh group found the same thing in their studies of 
bipolar (Himmelhoch et al, 1982, 1991; Thase et al, 1992) and imipramine-resistant nonbipolar (Thase et al, 1991) depressions.

In summary, mood reactivity appears to be a redundant and unnecessary criterion for diagnosis of atypical depression. Mood reactivity is a marker of a low level of depressive severity (Parker et al, 2002; Posternak and Zimmerman, 2002) and, as such, its association with atypical depression appears to have been an epiphenomenon. It is my recommendation that it be removed from the diagnostic criteria in DSM-V.

Future studies may fruitfully re-examine the potential utility of several of the other characteristics of preferential response to iproniazid described in the original reports on atypical depression (Sargant, 1960; West and Dally, 1959). As emotional over-reactivity is included in both older and newer descriptions, it might well be considered an alternate 'A' criterion. Indeed, approximately three-quarters of the atypical depression patients in the Columbia group's studies had rejection sensitivity and it was the most prevalent of the B criteria (McGrath et al, 1992). Angst et al (2002) similarly found that $80 \%$ of their patients with atypical depression reported rejection sensitivity. They also found that rejection sensitivity was the most stable of the DSM-IV diagnostic criteria over multiple depressive episodes.

Parker et al $(2002,2005)$ found evidence of significant associations between interpersonal sensitivity and several of the other DSM-IV B criteria for atypical depression, as well as associations with lifetime histories of social phobia and agoraphobia. Similarly, significant associations between atypical depression and anxiety disorders were reported by Posternak and Zimmerman (2001), Angst et al (2002), Matza et al (2003), and Novick et al (2005). The associations between early age of onset and interpersonal rejection sensitivity, and reverse neurovegetative symptoms and anxiety comorbidity point to fruitful avenues for genetic studies of vulnerability.

If rejection sensitivity proves to be a valid indicator of atypical depression, it would be worthwhile to consider a change in terminology, substituting a less gender-stereotyped term such as interpersonal sensitivity (Davidson et al, 1982). Although it is true that atypical depression tend to be more common in younger women (Angst et al, 2002; Thase et al, 1991) and apparent hypersensitivity to romantic setbacks may usefully 'map' on the troubles of younger depressed women, focusing only on one sex-typed behavioral pattern obscures the clinical reality that men and women with atypical depression experience a myriad of interpersonal difficulties, including sensitivity to criticism, avoidance, and fear of embarrassment in addition to rejection sensitivity.

Biological correlates. Earlier reviews of relevant neurobiological studies concluded that atypical depressions were not associated with the disturbances of hypothalamic-pituitary-adrenocortical (HPA) activity and sleep neurophysiology that typify melancholia (Rabkin et al, 1996; Stewart et al, 1993). Results of studies completed since the publication of DSM-IV are entirely consistent with this conclusion (Anisman et al, 1994; Bruder et al, 2002; McGinn et al, 1996; Stewart et al, 2005). However, beyond validating the obvious (ie, the conclusion that atypical depression is not melancholia), relatively little evidence can be marshaled to answer an equally important question 'How does atypical depression differ from nondepressed or normal states?' Research designed to definitively answer this question requires an age- and sex-matched healthy control group. Ideally, a comparison group consisting of depressed patients with other forms of depression would also be desirable, permitting examination of neurobiological profiles across two relevant dimensions (ie, depression (present $v s$ absent) and reverse neurovegetative features (present $v s$ absent)). As reviewed below, only a handful of relevant studies have included a normal control group.

In the only study of HPA activity to include a healthy control group, Anisman et al (1994) found that patients with atypical depression $(n=31)$ had significantly reduced morning plasma cortisol levels compared with both healthy control subjects $(n=27)$ and depressed patients who did not meet criteria for the atypical subtype $(n=14)$. Although the recent study Stewart et al (2005) did not include a normal control group, they found significantly lower afternoon cortisol concentrations in 20 patients with early onset/chronic atypical depression compared with $40 \mathrm{pa}$ tients with other forms of atypical depression (ie, later onset and/or episodic course). Thus, atypical depression may be associated with abnormally decreased HPA axis function and this finding may be limit to a subset of patients with early-onset, more chronic illnesses. These findings are of interest because, to my knowledge, decreased HPA function has been associated with only two other relevant neuropsychiatric conditions: chronic fatigue syndrome (Fries et al, 2005) and post-traumatic stress disorder (Newport et al, 2004).

Atypical depression also has been associated with a pattern of hemispheric asymmetry that appears to differ from both melancholics (Bruder et al, 1989, 2002; Fotiou et al, 2003) and normal controls (Bruder et al, 2002; Fotiou et al, 2003). In studies using a series of psychophysiological tasks, patients with atypical depression showed evidence of abnormally increased right hemispheric processing. In a secondary analysis of the Bruder et al (2002) study, which used a visual emotional processing task, the abnormal increase in right hemispheric processing were most pronounced in the subset of patients with an early age of onset and a chronic course (Stewart et al, 2003).

Evidence that atypical depression is associated with a characteristic biological profile, that is, both abnormal (ie, as compared with healthy controls) and distinct from melancholia, thus may be largely limited to the subset of patients with early onset/chronic illnesses. With respect to a possible association with post-traumatic stress disorder, Levitan et al (1998) reported a highly significant association between both reverse neurovegetative features and bipolarity with a history of childhood physical and sexual abuse. An intriguing pathoplastic hypothesis thus emerges. Both early trauma and a family history of bipolarity increase the likelihood of an early onset of depression. Developmental trauma may, in turn, blunt HPA responsivity, shaping the syndromal expression of the depressive disorder. 
Course of illness. Across studies, both clinical and epidemiologic, there is a wide agreement that atypical depression most typically has an early onset (ie, before age 21 years) and a chronic course (Stewart et al, 2009). As reviewed above, such an early onset, chronic presentation appears to be associated with a biological profile that distinguishes atypical depression from both normal controls and melancholics. An early age of onset of depression is also associated with a greater risks of chronicity, familial mood disorders, bipolarity, and anxiety and substance abuse comorbidities (see, eg, Zisook et al, 2004).

A more recent reanalysis of the treatment studies conducted by the Columbia group strongly suggests that the combination of an early age of onset and chronicity also may have important implications for differential therapeutics (Stewart et al, 2002). Specifically, in the studies that prospectively randomized patients with definite atypical depression to imipramine or phenelzine ( \pm placebo), the characteristically large advantage for the MAOI was evident only among the patients with the early onset/chronic atypical depressions (see Figure 1). In fact, although imipramine was no more effective than placebo in the atypical depression patients with an early onset and a chronic course, it was a highly effective treatment for the patients with other forms of atypical depression (Stewart et al, 2002). This pattern was confirmed in analyses of smaller subgroups of patients from a study of probable atypical depression (ie, mood reactivity and one associated symptom; see Quitkin et al, 1988), as well as in the study that crossed over nonresponders to phenelzine or imipramine to the alternate medication (see McGrath et al, 1993).

Another aspect of clinical course that is relevant to diagnostic validity is the propensity for illness subtypes to remain stable over time. A number of studies have documented that there is significant, although imperfect stability of the symptoms (Angst et al, 2002; Kendler et al, 1996; Nierenberg et al, 1996; Stunkard et al, 1990) and syndrome (Angst et al, 2002) of atypical depression. In the study of Angst, which followed a community sample from young adulthood to mid-life, the stability rates for atypical

Depressed Patients With Atypical Features

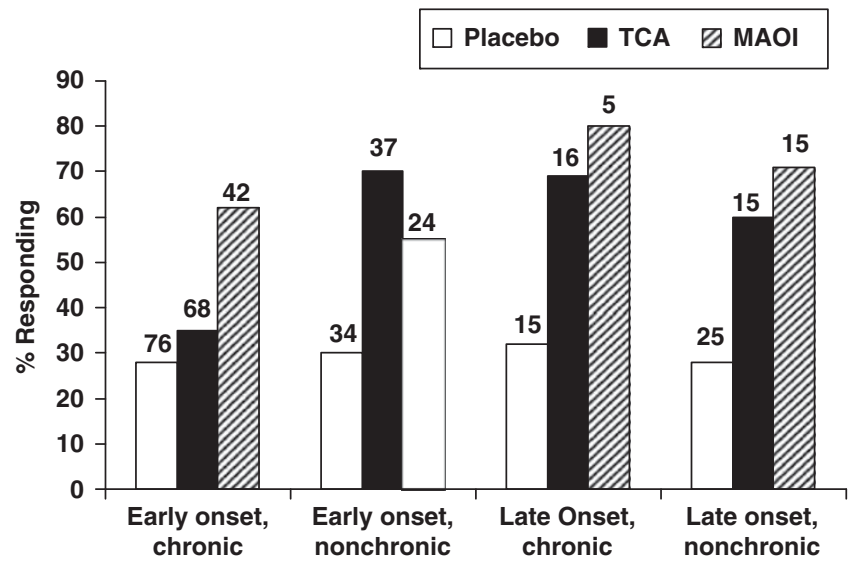

Figure I A secondary analysis of clinical course variables suggests that the advantage of phenelzine over imipramine in atypical depression is primarily explained by the subset of patients with early-onset, chronic depressive syndromes (Stewart et al, 2002). depression ranged from 46 to $64 \%$ across 2 - to 5-year intervals. Stability rates for the other, more 'typical' depressions ranged from 68 to $74 \%$ during the same time frames. Although formal tests of diagnostic reliability were not performed, it would appear that atypical depression was less stable than its counterpart.

With respect to the specific symptoms of atypical depression, Angst et al (2002) found that mood reactivity and leaden paralysis were the least stable of the DSM-IV criteria across multiple depressive episodes. Such relative instability of two of the five DSM-IV criteria for atypical depression no doubt adversely affects the stability of the syndrome across episodes. As mood reactivity is heavily dependent on global severity (Parker et al, 2002, 2005; Posternak and Zimmerman, 2002) - yet largely unrelated to the expression of the other symptoms of atypical depression-elimination of this criterion could significantly improve performance on this diagnostic validator. Moreover, as the characteristic symptoms of atypical depression and melancholia show somewhat opposite associations with age (ie, the former being more common among younger and the latter more common among older people with depression; Husain et al, 2005; Novick et al, 2005), further longitudinal study of younger patients with atypical depression would be worthwhile to try to disaggregate the pathoplastic effects of aging from those of depressive subtypes.

Treatment response. There is no dispute regarding the evidence that patients with atypical depression are more responsive to phenelzine than imipramine and, by implication, MAOIs are more effective treatments of atypical depression than TCAs (see, eg, the comprehensive reviews by Quitkin et al, 1993 and Thase et al, 1995). However, it is also true that the MAOIs are broadly effective antidepressants (Thase et al, 1995), whether or not patients have atypical features (Quitkin et al, 1989). With the added wisdom gleaned from re-analysis of Stewart et al (2002), it now appears that the advantage of phenelzine appears to be entirely attributable to the inferiority of imipramine for patients with early-onset/chronic forms of atypical depression, rather than the specific efficacy of phenelzine.

Regardless, it is fair to say that, in the $12+$ years that have followed the publication of DSM-IV, the significance of the relative advantage of MAOIs vs TCAs for early-onset/ chronic forms of atypical depression has diminished greatly, as neither class of antidepressant are now widely prescribed. A systematic review of studies with the newer antidepressants yields unfortunately little of relevance to this review (Henkel et al, 2006). Specifically, only a handful of studies of atypical depression have prospectively examined response to newer antidepressants such as the selective serotonin reuptake inhibitors (SSRIs) and these studies do not lead to any clear-cut conclusions.

One the one hand, the results of the meta-analysis of Henkel et al (2006) suggested that the SSRIs are as effective as the MAOIs. However, this was based on only three studies, of which the larger two used moclobemide rather than one of the older MAOIs. As moclobemide, a selective and reversible inhibitor of MAO A (RIMA), appears to be less effective than older MAOIs such as phenelzine and 
tranylcypromine (Lotufo-Neto et al, 1999), the metaanalysis may have overestimated the relative effectiveness of the SSRIs. Consistent with this, strong trends favored sertraline over moclobemide in the larger of the two studies of the RIMA (Sogaard et al, 1999). Nevertheless, it is true that in the only study to contrast an SSRI, fluoxetine $(n=20)$, with phenelzine $(n=20)$, both treatments were highly effective and tolerability indices favored the newer medication (Pande et al, 1996).

If, on the other hand, the SSRIs were indeed as effective as the older MAOIs, then they should also be more effective than TCAs for treatment of atypical depression. Little evidence has emerged to date in support of this speculation, although again there are only a small number of prospective comparative studies. The findings of Joyce et al (2002) are the most positive: in a post-hoc analysis of a reasonably large randomized controlled trial comparing the SSRI fluoxetine and the TCA nortriptyline, four of six of the atypical depression patients responded to fluoxetine as compared with none of 10 atypical depression patients treated with nortriptyline. This difference was statistically significant, but there are several concerns that limit confidence in the conclusion. First, as an uncommonly small proportion of their study group $(8 \% ; 16$ of 195$)$ were considered to have atypical depression, the accuracy of their classification is suspect. Second, the statistical significance of this comparison derives from the fact that none of the atypical depression patients responded to nortriptyline, which is an uncommonly bad outcome for a TCA that is not representative of the Columbia group's experience (eg, Quitkin et al, 1993). Third, response to nortriptyline was relatively low for all patients in this study, even among the subset of patients with melancholia (39\%).

In the largest $(n=154)$ published study to prospectively compare response to a TCA and an SSRI, the Columbia group was able to confirm that fluoxetine was significantly more effective than placebo (McGrath et al, 2000). They found no differences in efficacy between fluoxetine and imipramine; however, the SSRI was better tolerated than the TCA. Response rates were, in fact, almost identical; in the intent-to-treat analysis, for example, $51 \%$ of the fluoxetinetreated patients and $53 \%$ of the imipramine-treated patients responded to study therapy.

Results of an even larger, still unpublished study completed in the mid-1990s contrasting imipramine and sertraline in atypical depression are not known. However, in a preliminary report from this study focusing on anger attacks, the findings suggested that sertraline and imipramine were comparably effective (Fava et al, 1997). As the study's sponsor did not pursue publication of the full results, it seems unlikely that there was a significant advantage for sertraline over imipramine on the primary outcomes.

To my knowledge, there have been no prospective studies of other newer pharmacotherapies for atypical depression. This is unfortunate because bupropion and, to a lesser extent, venlafaxine, are widely prescribed to patients with reverse neurovegetative features.

Family history. Two studies have evaluated the heritability of atypical depression. Kendler et al (1996) conducted latent class analysis in a large study of twin pairs and identified a subgroup - defined by reverse neurovegetative symptoms- representative of atypical depression. They found significant concordance for the atypical depression subtype among monozygotic, but not dizygotic twin pairs. These data are clearly supportive of the construct of atypical depression, although they do not provide any support, one way or the other, for the DSM-IV criteria.

In a second family study, which included 475 pairs of siblings with a history of recurrent depression, a factor analysis of depressive symptoms was carried out, yielding four symptom factors. In addition to factors corresponding to the severity of affective disturbance, anxiety, and agitation/guilt/suicidal ideation, a fourth factor that included increased appetite and hypersomnia was identified. These results were replicated in a second factor analysis of an independent sample of depressed patients. Analysis of heritability showed that sibling pairs showed significant correlations for the first three factors, with coefficients of $0.15,0.34$, and 0.36 , respectively. By contrast, the fourth factor showed a weaker correlation (0.08), which did not reach the threshold for statistical significance $(p=0.052)$. Thus, although the results of the factor analysis supported the existence of the atypical depression construct, their findings suggested that reverse vegetative symptoms might be less heritable than other depression symptom factors.

\section{CONCLUSIONS}

This review acknowledges the historical significance of the concept of atypical depression, but takes issue with the DSM-IV criteria. Specifically, it is concluded that preservation of mood reactivity is neither significantly associated with the other symptomatic criteria nor valid as the essential or necessary criteria to diagnose atypical depression. The requirement of preserved mood reactivity artificially truncates the severity range of depressions with reverse neurovegetative features, leading to a false distinction between atypical depression and similar, although more severe, anergic depressive states. Moreover, as loss of mood reactivity is largely limited to patients meeting the DSM-IV criteria for melancholic features, it is suggested that preserved mood reactivity is redundant as a diagnostic criterion for atypical depression. Thus, in anticipation of DSM-V, it is suggested that the validity of atypical depression would be enhanced if the diagnosis were based on only two of the four remaining criteria (see, eg, Angst et al, 2006 or Posternak and Zimmerman, 2002).

Greater attention also needs to be paid to improve the reliability of the remaining criteria for atypical depression in preparation for DSM-IV. One can only wonder if the success of the Columbia group in studying atypical depression is attributable to the relative stability of the investigators and clinical evaluators across nearly two decades of research. To enhance the likelihood that their findings will be generalizable to other settings, however, better operational descriptions of interpersonal sensitivity and leaden paralysis are needed, and thresholds for what amount of change are necessary in order to have hypersomnia, increased appetite, or weight gain need to be carefully examined. If improved precision and greater 
reliability of the criteria could be achieved, then enhanced validity would no doubt follow.

Studies using psychophysiological tests of hemispheric activation suggest that early-onset, chronic episodes of atypical depressions appear to differ from both melancholia and normality. If true, different patterns of cerebral metabolism and regional blood flow should be observed on studies using more direct means of imaging brain function. The findings of one study using SPECT are suggestive of such differences; research employing more sensitive PET and fMRI scans is needed to confirm these findings: it is one thing to conclude that atypical depression is different than melancholia; it is quite another to identify a biological profile that distinguishes atypical depression from healthy normals, as well as melancholics. Future studies of biological processes should also focus on the potential relationship between atypical depression and anxiety, early age of onset, and genetic polymorphisms.

Perhaps the most striking conclusion of this review is based on more recent secondary analyses of the controlled treatment studies conducted by the Columbia group: the almost legendary advantage of phenelzine (and, presumably, other MAOIs) over imipramine (and, presumably, other TCAs) in atypical depression is explained by the subset of patients with an early age of onset and a chronic course. This finding may explain some of the discrepancies in the literature (ie, a study group consisting of patients with later illness onsets or a more episodic course of illness may show a better than expected TCA response) and dovetails nicely with secondary analyses of the Columbia group's psychophysiologic studies. As differential pharmacotherapy response was one of the dominant reasons for inclusion of atypical depression in DSM-IV, recognition that this pattern is delimited to a subset of patients suggests that age of onset and chronicity should be given careful consideration as secondary diagnostic criteria in DSM-V.

\section{DISCLOSURE}

Dr Thase received no financial support and reports no conflict of interest specifically related to this manuscript. However, as this paper pertains to the assessment and treatment of depression, Dr Thase does disclose the following relationships: during the past 3 years, he has been an advisor or consultant to AstraZeneca, Bristol-Myers Squibb Company, Eli Lilly \& Co., Forest Laboratories, GlaxoSmithKline, Janssen Pharmaceutica, MedAvante Inc., Neuronetics Inc., Novartis, Pfizer, Schering-Plough (formerly Organon), Shire US Inc., Supernus Pharmaceuticals, Transcept Pharmaceuticals, and Wyeth Pharmaceuticals. During this time period, he has received grant support from Eli Lilly \& Co., GlaxoSmithKline, and Sepracor Inc., as well as the National Institute of Mental Health. During the past 3 years, he has received honoraria for talks sponsored by AstraZeneca, Bristol-Myers Squibb Company, GlaxoSmithKline, Eli Lilly \& Co., and Wyeth Pharmaceuticals. He has equity holdings from MedAvante Inc. and has received royalties from American Psychiatric Publishing Inc., Guilford Publications, Herald House, and W.W. Norton \& Company Inc. Dr Thase's spouse is an employee of Advogent (Formerly Cardinal Health), who does business with several pharmaceutical companies that manufacture or promote medications approved for the treatment of depression.

\section{REFERENCES}

American Psychiatric Association (1994). Diagnostic and Statistical Manual of Mental Disorders (DSM-IV) 4th edn. American Psychiatric Association: Washington, DC.

Angst J, Gamma A, Sellaro R, Zhang H, Merikangas $\mathrm{K}$ (2002). Toward validation of atypical depression in the community: results of the Zurich cohort study. J Affect Disord 72: $125-138$.

Angst J, Gamma A, Benazzi F, Silverstein B, Ajdacic-Gross V, Eich D et al (2006). Atypical depressive syndromes in varying definitions. Eur Arch Psychiatry Clin Neurosci 256: 44-54.

Anisman H, Ravindran AV, Griffiths J, Merali Z (1994). Endocrine and cytokine correlates of major depression and dysthymia with typical or atypical features. Mol Psychiatry 4: 182-188.

Bruder GE, Quitkin FM, Stewart JW, Martin C, Voglmaier MM, Harrison WM (1989). Cerebral laterality and depression: differences in perceptual asymmetry among diagnostic subtypes. J Abnorm Psychol 98: 177-186.

Bruder GE, Stewart JW, McGrath PJ, Ma GJ, Wexler BE, Quitkin FM (2002). Atypical depression: enhanced right hemispheric dominance for perceiving emotional chimeric faces. J Abnorm Psychol 111: 446-454.

Davidson JR, Miller RD, Turnbull CD, Sullivan JL (1982). Atypical depression. Arch Gen Psychiatry 39: 527-534.

Fava M, Nierenberg AA, Quitkin FM, Zisook S, Pearlstein T, Stone A et al (1997). A preliminary study on the efficacy of sertraline and imipramine on anger attacks in atypical depression and dysthymia. Psychopharmacol Bull 33: 101-103.

Fotiou F, Fountoulakis KN, Iacovides A, Kaprinis G (2003). Pattern-reversed visual evoked potentials in subtypes of major depression. Psychiatry Res 118: 259-271.

Fries E, Hesse J, Hellhammer J, Hellhammer DH (2005). A new view on hypocortisolism. Psychoneuroendocrinology 30: 1010-1016.

Gillespie RD (1929). The clinical differentiation of types of depression. Guy Hosp Rep 79: 306-344.

Henkel V, Mergl R, Allgaier AK, Kohnen R, Moller JH, Hegerl U (2006). Treatment of depression with atypical features: a metaanalytic approach. Psychiatry Res 141: 89-101.

Henkel V, Mergl R, Coyne JC, Kohnen R, Allgaier AK, Ruhl E et al (2004). Depression with atypical features in a sample of primary care outpatients: prevalence, specific characteristics and consequences. J Affect Disord 83: 237-242.

Himmelhoch JM, Fuchs CZ, Symons BJ (1982). A double-blind study of tranylcypromine treatment of major anergic depression. J Nerv Ment Dis 170: 628-634.

Himmelhoch JM, Thase ME, Mallinger AG, Houck P (1991). Tranylcypromine versus imipramine in anergic bipolar depression. Am J Psychiatry 148: 910-916.

Horwath E, Johnson J, Weissman MM, Hornig CD (1992). The validity of major depression with atypical features based on a community study. J Affect Disord 26: 117-125.

Husain MM, Rush AJ, Sackeim HA, Wisniewski SR, McClintock $\mathrm{SM}$, Craven $\mathrm{N}$ et al (2005). Age-related characteristics of depression-a preliminary $\mathrm{STAR}^{\star} \mathrm{D}$ report. Am J Geriatr Psychiatry 13: 852-860.

Joyce PR, Mulder RT, Luty SE, Sullivan PF, McKenzie JM, Abbott $\mathrm{RM}$ et al (2002). Patterns and predictors of remission, response and recovery in major depression treated with fluoxetine or nortriptyline. Aus N Z J Psychiatry 36: 384-391.

Kendler KS, Eaves LJ, Walters EE, Neale MC, Heath AC, Kessler RC (1996). The identification and validation of distinct depressive 
syndromes in a population-based sample of female twins. Arch Gen Psychiatry 53: 391-399.

Klein DF, Davis JM (1969). Diagnosis and Drug Treatment of Psychiatric Disorders. Williams \& Wilkins: Baltimore.

Klein DF, Liebowitz MR (1982). Hysteroid dysphoria. Am J Psychiatry 139: 1520-1521.

Korszun A, Moskvina V, Brewster S, Craddock N, Ferrero F, Gill M et al (2004). Familiality of symptom dimensions in depression. Arch Gen Psychiatry 61: 468-474.

Levitan RD, Lesage A, Parikh SV, Goering P, Kennedy SH (1997). Reversed neurovegetative symptoms of depression: a community study of Ontario. Am J Psychiatry 154: 934-940.

Levitan RD, Parikh SV, Lesage AD, Hegadoren KM, Adams M, Kennedy SH et al (1998). Major depression in individuals with a history of childhood physical or sexual abuse: relationship to neurovegetative features, mania, and gender. Am J Psychiatry 155: $1746-1752$.

Liebowitz MR, Klein DF (1979). Hysteroid dysphoria. Psychiatr Clin North Am 2: 555-575.

Liebowitz MR, Quitkin FM, Stewart JW, McGrath PJ, Harrison WM, Markowitz JS et al (1988). Antidepressant specificity in atypical depression. Arch Gen Psychiatry 45: 129-137.

Lotufo-Neto F, Trivedi M, Thase ME (1999). Metaanalysis of the reversible inhibitors of monoamine oxidase type A moclobemide and brofaromine in the treatment of depression. Neuropsychopharmacology 20: 226-247.

Matza LS, Revicki DA, Davidson JR, Stewart JW (2003). Depression with atypical features in the National Comorbidity Survey: classification, description, and consequences. Arch Gen Psychiatry 60: 817-826.

McGinn LK, Asnis GM, Rubinson E (1996). Biological and clinical validation of atypical depression. Psychiatry Res 60: 191-198.

McGrath PJ, Quitkin FM, Harrison W, Stewart JW (1984). Treatment of melancholia with tranylcypromine. Am J Psychiatry 141: 288-289.

McGrath PJ, Stewart JW, Harrison WM, Ocepek-Welikson K, Rabkin JG, Nunes EN et al (1992). Predictive value of symptoms of atypical depression for differential drug treatment outcome. J Clin Psychopharmacol 3: 197-202.

McGrath PJ, Stewart JW, Harrison W, Wager S, Quitkin FM (1986). Phenelzine treatment of melancholia. J Clin Psychiatry 47: 420-422.

McGrath PJ, Stewart JW, Janal MN, Petkova E, Quitkin FM, Klein DF (2000). A placebo-controlled study of fluoxetine versus imipramine in the acute treatment of atypical depression. $A m \mathrm{~J}$ Psychiatry 157: 344-350.

McGrath PJ, Stewart JW, Nunes EV, Ocepek-Welikson K, Rabkin JG, Quitkin FM et al (1993). A double-blind crossover trial of imipramine and phenelzine for outpatients with treatmentrefractory depression. Am J Psychiatry 150: 118-123.

Newport DJ, Heim C, Bonsall R, Miller AH, Nemeroff CB (2004). Pituitary-adrenal responses to standard and low-dose dexamethasone suppression tests in adult survivors of child abuse. Biol Psychiatry 55: 10-20.

Nierenberg AA, Pava JA, Clancy K, Rosenbaum FJ, Fava M (1996). Are neurovegetative symptoms stable in relapsing or recurrent atypical depressive episodes? Biol Psychiatry 40: 691-696.

Novick JS, Stewart JW, Wisniewski SR, Cook IA, Manev R, Nierenberg AA et al (2005). Clinical and demographic features of atypical depression in outpatients with major depressive disorder: preliminary findings from $\mathrm{STAR}^{\star} \mathrm{D}$. J Clin Psychiatry 66: 1002-1011.

Pande A, Birkett M, Fechner-Bates S, Haskett R, Greden J (1996). Fluoxetine versus phenelzine in atypical depression. Biol Psychiatry 40: 1017-1020.

Parker G, Parker K, Mitchell P, Wilhelm K (2005). Atypical depression: Australian and US studies in accord. Curr Opin Psychiatry 18: 1-5.
Parker G, Roy K, Mitchell P, Wilhelm K, Malhi G, Hadzi-Pavlovic D (2002). Atypical depression: a reappraisal. Am J Psychiatry 159: $1470-1479$.

Pollitt J (1965). The diagnosis and management of depression. Practitioner 194: 597-604.

Posternak MA, Zimmerman M (2001). Symptoms of atypical depression. Psychiatry Res 104: 175-181.

Posternak MA, Zimmerman M (2002). Partial validation of the atypical features subtype of major depressive disorder. Arch Gen Psychiatry 59: 70-76.

Quitkin FM, Harrison W, Stewart JW, McGrath PJ, Tricamo E, Ocepek-Welikson K et al (1991). Response to phenelzine and imipramine in placebo nonresponders with atypical depression. A new application of the crossover design. Arch Gen Psychiatry 48: 319-323.

Quitkin FM, McGrath P, Liebowitz MR, Stewart J, Howard A (1981). Monoamine oxidase inhibitors in bipolar endogenous depressives. J Clin Psychopharmacol 1: 70-74.

Quitkin FM, McGrath PJ, Stewart JW, Harrison W, Wager SG, Nunes E et al (1989). Phenelzine and imipramine in mood reactive depressives. Further delineation of the syndrome of atypical depression. Arch Gen Psychiatry 46: 787-793.

Quitkin F, Rifkin A, Klein DF (1979). Monoamine oxidase inhibitors. A review of antidepressant effectiveness. Arch Gen Psychiatry 36: 749-760.

Quitkin FM, Stewart JW, McGrath PJ, Liebowitz MR, Harrison WM, Tricamo E et al (1988). Phenelzine versus imipramine in the treatment of probable atypical depression: defining syndrome boundaries of selective MAOI responders. $\mathrm{Am} J$ Psychiatry 145: 306-311.

Quitkin FM, Stewart JW, McGrath PJ, Tricamo E, Rabkin JG, Ocepek-Welikson K et al (1993). Columbia atypical depression. A subgroup of depressives with better response to MAOI than to tricyclic antidepressants or placebo. $\mathrm{Br} J$ Psychiatry 21: 30-34.

Rabkin JR, Stewart JW, Quitkin FM, McGrath PJ, Harrison WM, Klein DF (1996). Should Atypical Depression be Included in DSM -IV?. In: Widiger TA, Frances AJ, Pincus HA, Ross R, First MD, Davis WW (eds). DSM-IV Sourcebook. American Psychiatric Association: Washington, DC. Vol 2, pp 239-260.

Rush AJ, Gullion CM, Basco MR, Jarrett RB, Trivedi MH (1996). The Inventory of Depressive Symptomatology (IDS): psychometric properties. Psychol Med 26: 477-486.

Sargant W (1960). Some newer drugs in the treatment of depression and their relation to other somatic treatments. Psychosomatics 1: 14-17.

Sogaard J, Lane R, Latimer P, Behnke K, Christiansen PE, Nielsen B et al (1999). A 12-week study comparing moclobemide and sertraline in the treatment of outpatients with atypical depression. J Psychopharmacol 13: 406-414.

Stewart JW, Bruder GE, McGrath PJ, Quitkin FM (2003). Do age of onset and course of illness define biologically distinct groups within atypical depression? J Abnorm Psychol 112: $253-262$.

Stewart JW, McGrath PJ, Quitkin FM (2002). Do age of onset and course of illness predict different treatment outcome among DSM-IV depressive disorders with atypical features? Neuropsychopharmacology 26: 237-245.

Stewart JW, McGrath PJ, Quitkin FM, Klein DF (2009). DSM-IV depression with atypical features: is it valid? Neuropsychopharmacology (E-pub ahead of print 2 September 2009).

Stewart JW, Quitkin FM, McGrath PJ, Klein DF (2005). Defining the boundaries of atypical depression: evidence from the HPA axis supports course of illness distinctions. J Affect Disord 86: 161-167.

Stewart JW, McGrath PJ, Rabkin JG, Quitkin FM (1993). Atypical depression: a valid clinical entity? Psychiatr Clin North Am 16: 479-495. 
Stunkard AJ, Fernstrom MH, Price A, Frank E, Kupfer DJ (1990). Direction of weight change in recurrent depression. Consistency across episodes. Arch Gen Psychiatry 47: 857-860.

Sullivan PF, Prescott CA, Kendler KS (2002). The subtypes of major depression in a twin registry. J Affect Disord 68: 273-284.

Thase ME, Carpenter L, Kupfer DJ, Frank E (1991). Clinical significance of reversed vegetative subtypes of recurrent major depression. Psychopharmacol Bull 27: 17-22.

Thase ME, Mallinger AG, McKnight D, Himmelhoch JM (1992). Treatment of imipramine resistant recurrent depression: IV. A

See related article by Stewart et al on page 2625 . double-blind, crossover study of tranylcypromine in anergic bipolar depression. Am J Psychiatry 149: 195-198.

Thase ME, Trivedi MH, Rush AJ (1995). MAOIs in the contemporary treatment of depression. Neuropsychopharmacology 12: 185-219.

West ED, Dally PJ (1959). Effect of iproniazid in depressive syndromes. Br Med J 1: 1491-1494.

Zisook S, Rush AJ, Albala Z, Alpert J, Balasubramani GK, Fava M et al (2004). Factors that differentiate early $v s$. later onset of major depression disorder. Psychiatry Res 129: 127-140. 